\section{Journal of}

Gastroenterology
GE Port J Gastroenterol 2021;28:431-433

DOI: 10.1159/000510762
Received: April 27, 2020

Accepted: July 10, 2020

Published online: January 25, 2021

\title{
Rectal Tear: A Rare Cause of Gastrointestinal Bleeding
}

\author{
Isabel Garrido a,b Rui Morais ${ }^{a, b}$ Guilherme Macedo ${ }^{a, b}$ \\ ${ }^{a}$ Gastroenterology and Hepatology Department, Centro Hospitalar Universitário de São João, Porto, Portugal; \\ ${ }^{b}$ World Gastroenterology Organization (WGO) Porto Training Center, Porto, Portugal
}

Keywords

Rectal bleeding $\cdot$ Perianal disease $\cdot$ Rectal tear $\cdot$ Anorectal surgery

\section{Laceração retal: uma causa rara de hemorragia digestiva}

\section{Palavras Chave}

Hemorragia retal · Doença perianal · Laceração retal ·

Cirurgia anorretal

We present the case of a 52-year-old male with a past medical history of double-lung transplantation in the context of alpha- 1 antitrypsin deficiency, complicated by chronic lung allograft dysfunction (bronchiolitis obliterans syndrome), and two perianal interventions (fistulotomy and hemorrhoidectomy) 5 years before. The patient was admitted to our hospital due to acute-on-chronic respiratory failure as a result of respiratory infection.

In the intermediate care unit, he started noninvasive ventilation, broad-spectrum antibiotherapy, and thromboprophylactic enoxaparin $40 \mathrm{mg}$ daily. Due to constipation, even taking osmotic laxatives, daily docusate sodium and sorbitol enemas were initiated as well. Five days later, the patient had new-onset rectal bleeding, without

karger@karger.com www.karger.com/pjg

Karger"

BOPEN ACCESS (c) 2021 Sociedade Portuguesa de Gastrenterologia Published by S. Karger AG, Basel

This article is licensed under the Creative Commons AttributionNonCommercial-NoDerivatives 4.0 International License (CC BYNC-ND) (http://www.karger.com/Services/OpenAccessLicense). Usage and distribution for commercial purposes as well as any distribution of modified material requires written permission. abdominal or anal pain. Laboratory data showed a hemoglobin level of $6.4 \mathrm{~g} / \mathrm{dL}$. He required intravenous fluids and blood transfusions for resuscitation. Due to persistent rectal bleeding with associated hemodynamic instability, a flexible sigmoidoscopy was performed after cleansing enema administration.

An extensive tear of the distal rectum with exposure of the muscular layer was evident (Fig. 1a), as well as two fistula openings with many clots and associated spurting bleeding (Fig. 1b). Hemostasis was achieved after the injection of $9 \mathrm{~mL}$ of diluted adrenaline $(1: 10,000)$ and placement of 6 hemoclips (Fig. 2). Computed tomography angiography was performed immediately after the procedure, which showed parietal thickening of the terminal portion of the rectum, with associated fistulous tracts containing gas (Fig. 3). There was no evidence of active bleeding, perforation, or intra-abdominal collections. No further episodes of bleeding occurred after endoscopic therapy. However, the respiratory failure gradually worsened and the patient was refused for retransplantation. He died a week later.

Besides the previous perianal interventions, there was no history of recent trauma, anal intercourse, or endoscopic or surgical procedures. Therefore, the rectal tear was probably caused by the administration of a cleansing enema to a debilitated patient with reduced complaints of 

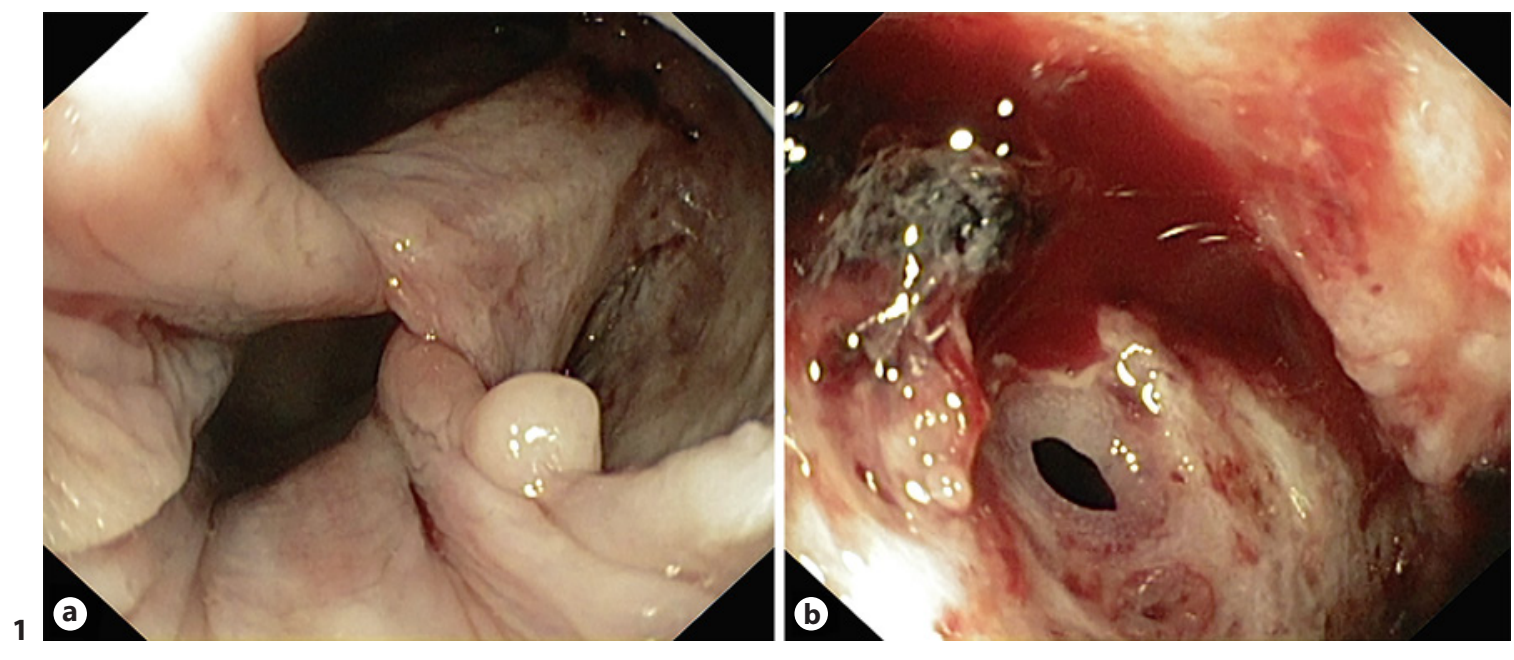

Fig. 1. Flexible sigmoidoscopy revealing an extensive rectal tear (a) and two fistula openings (b) in the area of ulceration, with associated active spurting bleeding.

Fig. 2. The bleeding was controlled after injection of diluted adrenaline and placement of clips.

Fig. 3. Coronal (a) and axial (b) view by abdominopelvic computed tomography angiography revealing parietal thickening of the distal rectum with associated fistulous tracts containing gas (arrows) and adjacent high-density material related to previous clip application.
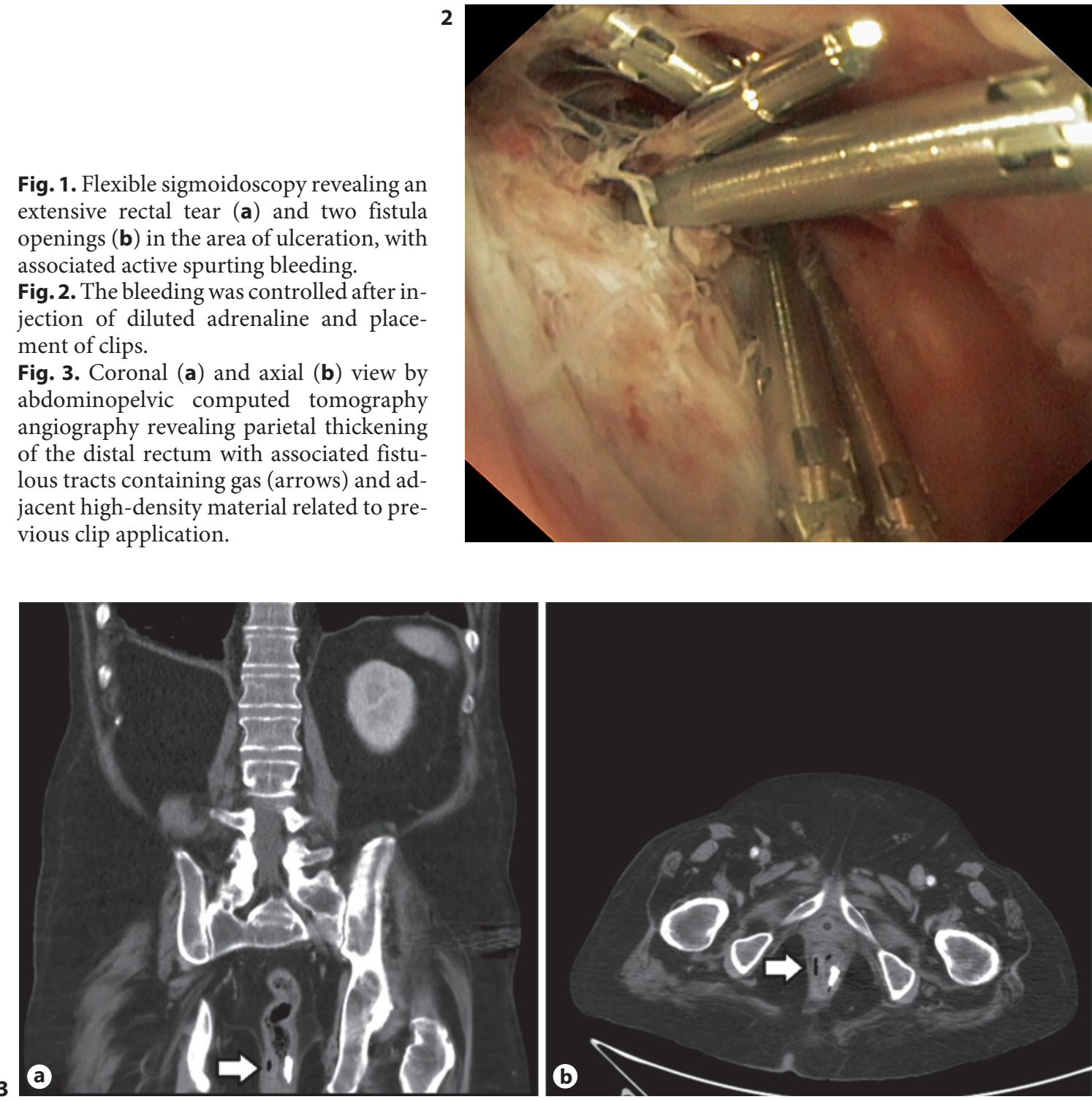
discomfort during the procedure, facilitated by premorbid perianal pathologies and chronic constipation. In fact, injuries to the anorectum, such as perforations, fistulae, and rectal burn, have already been described after enema administration [1-4]. Additionally, severe lower gastrointestinal bleeding has also been reported. The severity of the rectal bleeding can be explained by exposure of a submucosal vessel due to the rectal tear and the inpatient anticoagulation that was started on admission.

Cleansing enemas are widely used, especially in the treatment of chronic constipation. In the majority of cases, they produce the desired effect without any accompanying problems. However, the administration of a cleansing enema is not a risk-free procedure. Careless enema application, long rigid tips, and extant anorectal pathology have all been implicated as factors contributing to rectal injuries [1]. Therefore, any pre-existing perianal pathology must be identified, complaints of pain during the procedure require special attention, and oral laxatives may be preferred.

We reported a case of rectal tear with associated severe lower gastrointestinal bleeding, a potentially life-threatening complication of enema administration. This case emphasizes the need for careful application of enemas and highlights the importance of endoscopy as a potentially successful treatment of severe rectal bleeding.

\section{Statement of Ethics}

All rules of the local ethics committee were followed, preserving patient identity and confidentiality.

\section{Conflict of Interest Statement}

The authors have no conflicts of interest to declare.

Funding Sources

The authors have no funding sources to declare.

\section{Author Contributions}

Isabel Garrido did the literature review and drafted the manuscript. All authors have critically revised and finalized the manuscript and have approved the final version of the manuscript.

\section{References}

1 Saltzstein RJ, Quebbeman E, Melvin JL. Anorectal injuries incident to enema administration. A recurring avoidable problem. Am J Phys Med Rehabil. 1988 Aug;67(4):186-8.

2 Mori H, Kobara H, Fujihara S, Nishiyama N, Kobayashi M, Masaki T, et al. Rectal perforations and fistulae secondary to a glycerin enema: closure by over-the-scope-clip. World J Gastroenterol. 2012 Jun;18(24):3177-80.
3 Kye BH, Kim HJ, Lee KM, Cho HM. Intractable rectal stricture caused by hot water enema. J Korean Surg Soc. 2011 Nov;81(5):3504.

4 Niv G, Grinberg T, Dickman R, Wasserberg N, Niv Y. Perforation and mortality after cleansing enema for acute constipation are not rare but are preventable. Int J Gen Med. 2013 Apr;6:323-8. 